\title{
Robust Production Planning in Fashion Apparel Industry under Demand Uncertainty via Conditional Value at Risk
}

\author{
Abderrahim Ait-Alla, ${ }^{1}$ Michael Teucke, ${ }^{1}$ Michael Lütjen, ${ }^{1}$ \\ Samaneh Beheshti-Kashi, ${ }^{1}$ and Hamid Reza Karimi ${ }^{2}$ \\ ${ }^{1}$ Bremer Institut für Produktion und Logistik GmbH at the University of Bremen (BIBA), 28359 Bremen, Germany \\ ${ }^{2}$ Department of Engineering, Faculty of Technology and Science, University of Agder, 4898 Grimstad, Norway \\ Correspondence should be addressed to Michael Teucke; tck@biba.uni-bremen.de
}

Received 31 January 2014; Accepted 25 March 2014; Published 29 April 2014

Academic Editor: Michael Freitag

Copyright (C) 2014 Abderrahim Ait-Alla et al. This is an open access article distributed under the Creative Commons Attribution License, which permits unrestricted use, distribution, and reproduction in any medium, provided the original work is properly cited.

\begin{abstract}
This paper presents a mathematical model for robust production planning. The model helps fashion apparel suppliers in making decisions concerning allocation of production orders to different production plants characterized by different lead times and production costs, and in proper time scheduling and sequencing of these production orders. The model aims at optimizing these decisions concerning objectives of minimal production costs and minimal tardiness. It considers several factors such as the stochastic nature of customer demand, differences in production and transport costs and transport times between production plants in different regions. Finally, the model is applied to a case study. The results of numerical computations are presented. The implications of the model results on different fashion related product types and delivery strategies, as well as the model's limitations and potentials for expansion, are discussed. Results indicate that the production planning model using conditional value at risk $(\mathrm{CVaR})$ as the risk measure performs robustly and provides flexibility in decision analysis between different scenarios.
\end{abstract}

\section{Introduction}

This contribution deals with production planning problems of fashion apparel products. Fashion apparel products belong to the most important consumer goods. Global retail revenues amounted to $\$ 1,032$ billion in 2009 and are expected to grow to $\$ 1,163$ billion by 2016 [1].

Production planning for fashion apparel products has to cope with demand uncertainties. Accordingly, the uncertain nature of the customer demand has to be taken into consideration by generating the production plan and in particular the production quantities, in order to meet uncertain customer demand in the best way possible and maximize the profit, by minimizing production costs.

In this case, production planning, in particular the correct placement of production orders concerning place, or region, of production, as well as time scheduling and sequencing of production orders, is of high economic importance for fashion apparel suppliers. However, at the time of generating the production plan, the predicted customer demands are largely uncertain. Therefore, it is crucial to produce a robust production plan, which can manage the risk resulting from the demand forecast. This risk trade-off can be achieved by constraining the objective function or problem limits with $\mathrm{CVaR}$. Indeed, $\mathrm{CVaR}$ intends to protect against undesirable realization of uncertain parameters beyond the expected evaluation due to the uncertainty of system parameters [2].

Existing papers dealing with the robust optimization in fashion apparel do not take into account the risk of losing more than an acceptable level of profits due to write-offs caused by an overly optimistic demand forecast, or earning less than a desired target profit due to an overly pessimistic demand forecast. This paper is the first study to address this problem for the fashion apparel industry.

To deal with this uncertainty in customer demand in the apparel industry, we propose a risk-constrained profitexpected maximization model. This model considers the stochastic nature of customer demand and generates a production plan which indicates the quantities of each product 
that should be produced, the start of the production of each product, and the facility in which the products have to be produced. The objective is to maximize the total profit of productions by means of $\mathrm{CVaR}$.

Consideration of risk in the optimization problem has a crucial role in optimization under uncertainty, particularly when the optimization problem has to deal with the losses that might be incurred under conditions of unfavorable demand. To consider the risk of erroneous demand forecasts, a loss function $f(X, s)$ will be defined, where $X$ represents a decision vector and $s$ is a vector representing uncertainty related to the future values of a number of stochastic parameters of the problem. These stochastic parameters, presented by the vector $s$, are governed by probability distribution $P_{s}$. Once the loss function $f$ is defined, we denote the distribution function of $f$ by $\varphi(X, \beta):=P\{s \mid f(X, s) \leq \beta\}$, which corresponds to the probability that the value of the loss function, for each realisation of a scenario of the vector $s$, and for a fixed $X$, does not exceed the value $\beta$. In this context, for a specified confidence value $\alpha \in[0,1$ [, that could be equal to 0,90 or 0,95 in some applications, $\alpha$-VaR denotes the probability that the expected value of the loss function exceeds $\beta$ only in $(1-\alpha) \cdot 100 \%$ for all possible realisations of stochastic parameters, which can be seen as the worstcase scenario. Based on the definition of value at risk (VaR), conditional value at risk $(\mathrm{CVaR})$ is defined as the mean of the tail distribution exceeding VaR [3].

The model is applied to a problem based on a case study in the apparel industry. Different factories located in different countries manufacture a number of product types and sell these products to customers in Europe. The orders consist of the type of products, delivery date, and quantity. Usually, the quantity demand of a product $i$ is of stochastic nature and having a probability distribution $p(i)$. After collecting orders, the production plan has to be generated for the next season by considering the manufacturing capacity, production cost, and transport cost while satisfying a CVaR constraint in order to maximize the expected total profit.

In order to generate different possible demand realisations for the mathematical model, different scenarios of $\Omega$ are generated by means of Monte Carlo simulation, using the demand probability distribution of each product within the set of products.

The paper is structured as follows: the next chapter will provide some additional information on production planning and demand uncertainty in the apparel industry. The subsequent chapter studies some of the literature on robust production planning under demand uncertainty. After that, our model will be described and subsequently applied to a case study that includes three scenarios (a pessimistic scenario, a normal scenario, and an optimistic scenario) differing in customer demand. These three scenarios have been proposed in order to cover different potential realizations of customer demand, which can occur but are not known at the time of planning. Thereby, the customer demand can be estimated as low (pessimistic estimate), normal (normal estimate), or high (optimistic estimate), based on historic data and the recommendations of experts. The paper ends with a conclusion and an outlook on further research.

\section{Production Planning and Demand Uncertainty in Apparel Industry}

Manufacturing and finishing of ready-to-wear garments are a complex process involving often a large number of collaborating parties within a production network [4]. These include garment manufacturers and their raw material suppliers, procurement agencies, logistic service providers, and retailers [5].

Due to limited potential for automation and price importance in competition, production of fashion apparel products has been largely outsourced to low wage countries, often situated either in East Asia, the Near East, in particular in China, Turkey, Bangladesh, India, and Vietnam. Due to the absence of technical constraints and availability of subcontractors, production can be shifted with few constraints between different regions. However, the large majority of the products are still sold in Europe and North America, even though rising domestic demand in Asian countries, such as China, has started to increasingly compete for local production resources [6-8]. In this context, many European garments suppliers have reduced the depth of their own production, or dropped it, and have adapted their role towards planning and coordinating activities within apparel supply chains, integrating garment manufacturers and raw materials suppliers, logistic service providers, and retailers [9]. The wide geographic distribution of supply chains results in considerable lead times of apparel production, due to the time needed for procurement of raw materials, and the time needed for transport of products from the production plants to the customers $[10,11]$.

In addition to low product costs, quality and reliability of logistic services are crucial for economic success in the apparel branch. Fashion apparel products are characterized by rapid product obsolescence. The sales seasons for a period of a few months or even weeks are short in comparison to their long production lead and delivery times. This increases the importance of adherence to delivery dates. On average, $95 \%$ of stock keeping units change for every new sales season, at least twice or four times a year $[5,12]$. The production cycle is characterized by fixed seasonal cycles with fixed dates for product offers, orders, and deliveries, which are repeated production volumes based on aggregation of the retail preorders. However, as in practice production and distribution lead times usually exceed the length of the delivery times expected by customers, production planning and procurement of raw materials have to start before the end of the preorder period, using forecasts of total demand based on the orders arrived so far. Products may also be produced in larger quantities than if only based on preorders, with the excess offered directly from the warehouses to called postorders as long as stocks last [13].

Once their sales season has ended, articles, which have not been sold so far, can be sold only for reduced prices and thus with reduced profit in the next season. Thus, at the end of a sales season, the stock levels of the products should ideally be close to zero. On the other hand, stocks should not run out before the end of the sales period. Reproduction of successful products during a sales season is not possible due to the long 
delivery times [12]. For these reasons, demand forecasting has to be considered an important input of production planning and supply chain planning models. Generally, forecasting of potential sales permeates all aspects of business operations [14]. Customer demand for fashion products is volatile and may vary broadly for different variants of the same product. Demand fluctuations are difficult to predict at the time of production planning. Optimistic forecasts may lead to overstocks and higher production costs and cause markdowns. Pessimistic forecasts may lead to loss of opportunity revenues for potential sales that could not be realized and to customer dissatisfaction with later brand changes.

On the other hand, traditional statistical forecasting methods are difficult to apply [15]. Specifically developed demand forecasting models often use soft computing methods, such as artificial neural networks [16], fuzzy logic, and evolutionary procedures $[12,17]$. In addition, the integration of preorder information as well as expert judgments has produced accurate forecasts [18]. Most of these models have not been integrated into standard business software and are difficult to use, with sometimes mixed quality of the forecasts. Order fulfilment and product delivery failures, such as stockouts, or increased storage costs and product depreciation write-offs continue to affect profits in the apparel branch in a very unfavourable way. It is estimated that, due to the long lead times and demand forecasting difficulties mentioned in the second section of this chapter, up to $30 \%-40 \%$ of highfashion articles cannot be sold during the short sales season before the life expectancy of the article expires [19]. The need to cope with this situation and the impetus to realize Quick Response concepts have resulted in vertical integration of apparel suppliers and retailers in a number of cases [20]. Vertically integrated suppliers generally achieve better reaction to market changes due to shortened reaction times and more closely integrated information flows. However, these advantages cannot easily be copied by most traditional suppliers, which are often small or medium sized enterprizes. Still, it is estimated that they have to write off up to $15 \%-20 \%$ of their high-fashion articles [19].

\section{Literature Review on Problem Related Production Planning}

Production and distribution operations are two key functions in the supply chain. In general, the supply chain management procedures emphasize production scheduling more than the distribution scheduling, because distribution is more flexible. When integrated supply chain management of production and distribution is realized, the resources are used more efficiently [21]. In a comprehensive review of integrated scheduling approaches Mula et al. showed that over 44 papers have been published between 1989 and 2009 [22].

In general, master, tactical, and operational planning levels can be separated. The purpose of most models is to minimize the total cost of the supply chain. Some work at the master planning level, integrating procurement in addition to production and distribution scheduling, is described in [23]. Most of the models focus on tactical planning, considering different demand levels, costs, and capacities, and use centralized scheduling approaches. Scholz-Reiter et al. showed a scalable graph-based scheduling approach, which is focused on the operational level and real-time scheduling [24]. A large variety of OR techniques have been applied, comprising mathematical optimisation, heuristics, and metaheuristics, but it could be observed that most of the papers focus on deterministic solutions [22].

The special conditions of production planning for fashion products have received some studies as well. The work in [25] described a networked production planning process in a fashion oriented apparel supply chain. The production planning process was found to be an important area of improvement for a network in a time-based logic; shortening the production planning period, in fact, significantly affects the weighted average delivery anticipation. It leads, however, to increase setup and transportation costs due to the greater number of jobs generated during a campaign. Scheduling of integrated production and distribution systems in dynamic environments holds a potential to improve efficiency but also poses a challenging planning task due to its computational complexity. Long lead times, external and internal perturbations in productive processes, unstable business environments, and contextual differences (e.g., institutional, economic, and cultural) emphasize the relevance to the argued integration [26]. Three types of aggregate production planning methods for the apparel industry have been proposed in [27]. These allow changing a production model seasonally according to actual demands, or maintaining the same production model for several seasons with production for inventory. The mentioned work on integrated production and distribution planning does not deal with stochastic input data, such as demands. The work in [28] studied empirically the impact of the subsidy policy on total factor productivity for the example of Chines cotton production.

Modern, large, and widely distributed production networks are subject to many forms of disturbances. Karimi, Duffy, and Dashkovsky et al. performed research on how to better deal with such dynamic influences. One possible solution is to introduce autonomous control, that is, to allow some parts of a large network to make their own decisions based on local situation and available information. However, stability of the network and robustness with respect to external and internal disturbances and time delays in signals must be assured to guarantee a reasonable performance and vitality of the whole system. For this purpose their work proposed an approach for controller design for large scale autonomous work systems capable of coping with time delays and explains its implementation and advantages on a concrete example [29-31].

Robust optimization models try to formulate production planning problems in a way that cost, or wastage, effects of uncertainty or risks are minimized or expected profit is maximized. A robust optimization model for a multisite production medium-term planning problem is developed in [32], based on the problems facing a multinational lingerie company with production sites in East Asia. It generates a cost minimal production plan for an uncertain environment with associated probabilities of different economic growth 
scenarios. The cost minimal production plan is less sensitive to changes in the noisy and uncertain data. The work in [33] dealt with a portfolio selection model in which the methodologies of robust optimization are used for the minimization of the conditional value at risk of a portfolio of shares. The work in [34] proposed a method for robust self-scheduling based on CVaR. The proposed method is based on a securityconstrained optimal power flow (SCOPF) program that explicitly treats the trade-off between risk and reward. The work in [35] proposed a fuzzy mathematical programming model for supply chain planning which considers supply, demand, and process uncertainties. The model has been formulated as a fuzzy mixed-integer linear programming model where data are ill-known and modelled by triangular fuzzy numbers. The fuzzy model provides the decision maker with alternative decision plans for different degrees of satisfaction. This proposal is tested by using data from a real automobile supply chain. A supply chain design problem for a new market opportunity with uncertain demand in an agile manufacturing setting is considered in [36]. This model integrates the design of supply chain and production planning for the supply chain's members and develops a robust optimization formulation. A novel framework based on conditional value at risk theory has been applied in [37] to the problem of operational planning for large-scale industrial batch plants under demand due date and amount uncertainty. The objective of the proposed model is to provide a daily production profile that not only is a tight upper bound on the production capacity of the plant but also is immune to the various forms of demand uncertainty. In further work, The work in [38] applied a robust optimization framework, as well as CVAR theory to the multisite operational planning problem under multiple forms of system uncertainty. They considered different forms of system uncertainty such as demand due date, demand amount, and transportation time uncertainty in the model. Their objective is to ensure the maximization of customer satisfaction along with the minimization of resource misallocation.

A robust multiobjective mixed integer nonlinear programming model is proposed by [39] to deal with a multisite, multiperiod, multiproduct aggregate production planning (APP) problem under uncertainty, considering two conflicting objectives simultaneously, as well as the uncertain nature of the supply chain. Their proposed model is solved as a single-objective mixed integer programming model applying the LP-metrics method. A two-stage real world capacitated production system with lead time and setup decisions uncertain production costs and customer demand is studied in [40], using a robust optimization approach. A mixed-integer programming (MIP) model is developed to minimize total production costs.

\section{Description of the Model}

Our model maximizes expected profits in scenarios of stochastic customer demand. The model generates production plans containing the production quantities of each product of a given product program, the production start of each product, and the production plants where the products should be produced.

Notation. A set $I$ of $n$ products has to be manufactured, under restriction of several time and resource constraints. The forecast demand of each product to be manufactured is uncertain and a probabilistic distribution is used to characterize this uncertainty. The manufacturing of different products has to take place in just one of $m$ different facilities located in different countries.

A facility $j \in J$ has a fixed production cost $\mathrm{CP}_{i j}$ to produce the product $i$, a fixed transport cost $\mathrm{CT}_{j}$, and a production capacity $\mathrm{CAP}_{i j}$ of products which can be manufactured during one period.

A product $i \in I$ has a delivery due date $\mathrm{DD}_{i}$, and if it is supplied earlier than the recommended $\mathrm{DD}_{i}$ that would cause extra holding costs $\mathrm{CH}_{i}$, and if it is supplied later than the due date $\mathrm{DD}_{i}$ that would cause penalty costs $\mathrm{PEC}_{i}$.

The objective is to find a feasible plan, which determines the quantity of each product to be produced and indicates the start of production of each product $i$, manufactured from facility $j$, to fulfil the stochastic demand and maximize the total production profit.

Parameters. In the following, the parameters for the model are defined.

$T$ is set of planning periods, where $k=|T|$.

$t$ is index of the planning period $t \in\{1, \ldots k\}$.

$J$ is set of facilities, where $m=|J|$.

$j$ is index of facility $j \in\{1, \ldots m\}$.

$I$ is set of products, where $n=|I|$.

$i$ is index of product $i \in\{1, \ldots n\}$.

$\Omega$ is set of all possible scenarios of stochastic variables $\Omega=\{1,2, \ldots, S\}$.

$s$ is index of scenario res. Realisation of stochastic variables $s \in[1, S]$, where $S:=|\Omega|$

$D_{i}^{s}$ is the demand of product $i$ under scenario $s$.

$P_{s}$ is probability of scenario $s$.

$\mathrm{SP}_{i}$ is the unit selling price for product $i$.

$\mathrm{CP}_{i j}$ is the unit production cost for product $i$ manufactured in facility $j$.

$\mathrm{CT}_{j}$ is transport cost from the facility $j$ in terms of number of periods.

$\mathrm{CH}_{i}$ is the unit inventory holding cost for product $i$ at the end of production.

$\mathrm{SL}_{i}$ is salvage value per unit for product $i$.

$\mathrm{SR}_{i}$ is shortage penalty per unit for product $i$.

$\mathrm{TT}_{j}$ is transport time from the facility $j$ in terms of number of periods.

$\mathrm{DD}_{i}$ is delivery due date of product $i$ in terms of number of periods. 
$\mathrm{PF}_{i}$ is penalty cost incurred to each late delivery for product $i$ when it is supplied later than the delivery date $\mathrm{DD}_{i}$.

$\mathrm{CAP}_{i j}$ is production capacity (units) for product $i$ during a period in facility $j$.

$\alpha$ is confidence level of risk parameter CVaR, where $\alpha \in[0,1[$.

$\beta$ is risk parameter.

$\lambda$ is weight presented on solution variance.

$\mu$ is weight placed on model infeasibility which controls the trade-off between solution and model robustness.

Variables. Consider the following.

$X_{i}$ is quantity of product $i$ that shall be produced (decision variable).

$Y_{i j}$ is binary variable, which indicates whether product $i$ is produced in facility $j$ (decision variable).

$\mathrm{STP}_{i}$ is start period of the production of product $i$ (decision integer variable);

$\mathrm{TP}_{i}$ is time required in periods to produce $X_{i}$ of product $i \mathrm{TP}_{i}=\sum_{j=1}^{m} Y_{i j}\left(X_{i} / \mathrm{CAP}_{i j}\right)$

$\operatorname{ExpEnd} P_{i}$ is expected delivery date of product $i$ in period unit; ExpEnd $P_{i}=\mathrm{STP}_{i}+\mathrm{TP}_{i}+\sum_{j=1}^{m} Y_{i j} \cdot \mathrm{TT}_{j}$

$\mathrm{MIN}_{i}^{s}$ is quantity of product $i$ effectively sold under scenario $s . \mathrm{MIN}_{i}^{s}=\min \left(X_{i}, D_{i}^{s}\right)$.

WAS $_{i}^{s}$ is wastage quantity of product $i$ under scenario $s . \mathrm{WAS}_{i}^{s}=\max \left(0, X_{i}-D_{i}^{s}\right)$.

$\mathrm{SHO}_{i}^{s}$ is shortage quantity of product $i$ under scenario s. $\mathrm{SHO}_{i}^{s}=\max \left(0, D_{i}^{s}-X_{i}\right)$.

$I_{i}$ is binary variable, which indicates whether the product $i$ has to be held or not after its production and transportation:

$$
I_{i}= \begin{cases}1, & \text { if } \operatorname{ExpEnd} P_{i}<\mathrm{DD}_{i} \\ 0, & \text { else. }\end{cases}
$$

Objective Function. The objective function has the following components:

(1) sales revenue,

(2) production cost,

(3) transport cost,

(4) holding cost,

(5) penalty cost due to a late delivery,

(6) risk cost incurred for possible wastage cost,

(7) risk cost incurred for possible shortage cost.

The above components have been considered due to the fact that they are the most important costs which can be mainly affected by the decision variable of the model.
The objective is to maximize the total profit revenue consisting of sales revenue gained by selling the products, production (PC), transport (TC), penalty, holding (HC), and other risk costs which can be incurred for possible wastage or shortage quantities:

$$
\begin{aligned}
\left.\mathrm{SR}^{s} \text { (sales revenue }\right) & =\sum_{i=1}^{n} \mathrm{MIN}_{i}^{s} \cdot \mathrm{SP}_{i}, \\
\mathrm{PC}(\text { production cost }) & =\sum_{i=1}^{n} \sum_{j=1}^{m} Y_{i j} \mathrm{X}_{i} \mathrm{CP}_{i j}, \\
\mathrm{TC}(\text { transport cost }) & =\sum_{i=1}^{n} \sum_{j=1}^{m} Y_{i j} X_{i} \mathrm{CT}_{j},
\end{aligned}
$$

$\mathrm{HC}($ holding cost $)=\sum_{i=1}^{n}\left\{I_{i} \cdot\left(\mathrm{DD}_{i}-\operatorname{ExpEnd} P_{i}\right) \cdot X_{i} \mathrm{CH}_{i}\right\}$,

PEC (penalty cost)

$$
\begin{aligned}
& =\sum_{i=1}^{n}\left\{\left(1-I_{i}\right)\left(\operatorname{ExpEnd} P_{i}-\mathrm{DD}_{i}\right) X_{i} \mathrm{PF}_{i}\right\} \\
& \mathrm{WC}^{s}(\text { wastage cost })=\sum_{i=1}^{n} \mathrm{WAS}_{i}^{s} \cdot \mathrm{SL}_{i}, \\
& \mathrm{SC}^{s}(\text { shortage cost })=\sum_{i=1}^{n} \mathrm{SHO}_{i}^{s} \cdot \mathrm{SR}_{i} .
\end{aligned}
$$

Equation (2) represents the total sales revenue due to selling the set of products $I$. Equation (3) is the total production cost of manufacturing the set of products $I$. Equation (4) is the total transport cost of the set products $I$. Equation (5) corresponds to the total holding cost of units of products, which has to be stored in the warehouses for a determined holding period. Equation (6) represents the total penalty cost of supplying the set of products $I$ later than the appropriate delivery date. Equation (7) represents the wastage cost to liquidate the overstocks set of products $I$. Equation (8) represents an artificial penalty for the demand dissatisfaction and subsequently to loss of opportunity revenue.

The following formulation of robust problem is defined according to Leung et al. [32].

We denote the profit function for each scenario $s$ with

$$
F_{s}=\left[\mathrm{SR}^{s}+\mathrm{WC}^{s}-\mathrm{SC}^{s}-\mathrm{PC}-\mathrm{TC}-\mathrm{HC}-\mathrm{PEC}\right] .
$$

The objective function, which represents the maximizing expected profit of the production planning problem with the demand uncertainty, is formulated as follows:

$$
\begin{gathered}
\max E \text { [profit] } \\
=\max \left\{\sum_{s=1}^{\Omega} p_{s} F_{s}+\lambda \sum_{s=1}^{\Omega} p_{s}\left[F_{s}-\sum_{s^{\prime}=1}^{\Omega} p_{s^{\prime}} F_{s^{\prime}}\right]\right. \\
\left.+\mu \sum_{s=1}^{\Omega} p_{s} \theta_{s}\right\} .
\end{gathered}
$$


The first term of $(10)$ is the mean value of the total profit. The second term of (10) denotes the measure solution robustness of the model. The third term in (10) represents the model robustness and is used to penalize model infeasibility.

Constraints. First, we define the loss function as follows:

$$
\forall s \in \Omega, \quad f(X, s)=\sum_{i=1}^{n} f\left(X_{i}, s\right)=\mathrm{WC}^{s}+\mathrm{SC}^{s}-\beta \cdot \mathrm{SR}^{s} .
$$

The objective function is subject to the following constraints:

$$
\begin{gathered}
\forall i \in I, \quad \operatorname{ExpEnd} P_{i} \leq k, \\
\forall i \in I, \quad \sum_{j=1}^{m} Y_{i j}=1, \\
\forall i \in I, \quad \operatorname{STP}_{i}>0, \\
\forall i, i^{\prime} \in I, \quad \text { if } \exists \mu \in J \text { so that } Y_{i \mu}=Y_{i^{\prime} \mu}=1, \\
\operatorname{STP}_{i}<\operatorname{STP}_{i^{\prime}} \text { then } \operatorname{STP}_{i^{\prime}} \geq \operatorname{STP}_{i}+\operatorname{TP}_{i}, \\
\forall s \in \Omega, \quad P[s \mid f(X, s) \leq 0] \leq \alpha .
\end{gathered}
$$

Constraint (12) ensures that the expected delivery date for all products should not exceed the length of the planning horizon $k=|T|$. Constraint (13) guarantees that the production of a product $i$ will take place only in one facility $j$. Constraint (14) indicates that the start of production of a product $i$ is positive and integer. Constraint (15) ensures that the production of more than one product cannot be carried out in a parallel manner. Constraint (16) restricts the probability of the loss function to be negative, for $\alpha \cdot 100 \%$, which means that the undesirable realization of uncertainties can restrict the loss function to be positive in only $(1-\alpha)$. $100 \%$. As an example, for $\alpha=0.95$ the constraint (16) has to be satisfied for $95 \%$ for all possible realizations of demand $D_{i}^{s}$ for all $i \in I$ and for all $s \in \Omega$.

\section{Experimental Results for a Case Study with Three Scenarios}

In order to cover different potential realizations of customer demand, three scenarios have been selected, including a "pessimistic" scenario characterized by assumed low customer demand, a "normal" scenario characterized by average customer demand, and an "optimistic" scenario characterized by relatively high customer demand. These three scenarios take into account the insecurity concerning customer demand for the products. Different values have been chosen based on data taken from a real case study.

In this section we analyze the behavior of the model by means of a case study based scenario. The input data parameters of the model are summarized in Tables 1 and 2.

\begin{tabular}{|c|c|c|c|c|}
\hline & Product 1 & Product 2 & Product 3 & Product 4 \\
\hline \multicolumn{5}{|l|}{ Production } \\
\hline Minimum value & 10000 & 7500 & 5000 & 8000 \\
\hline Maximum value & 40000 & 30750 & 20750 & 31600 \\
\hline \multicolumn{5}{|l|}{ Production cost } \\
\hline Facility 1 & 1 & 1 & 2 & 2 \\
\hline Facility 2 & 3 & 2 & 3 & 5 \\
\hline \multicolumn{5}{|l|}{ Capacity } \\
\hline Facility 1 & 20000 & 20000 & 20000 & 20000 \\
\hline Facility 2 & 10000 & 10000 & 150000 & 10000 \\
\hline Penalty factor $\mathrm{PF}_{i}$ & 0.1 & 0.2 & 0.8 & 0.5 \\
\hline Delivery due date $\mathrm{DD}_{i}$ & 6 & 6 & 6 & 6 \\
\hline Shortage cost unit & 5 & 4 & 5 & 9 \\
\hline Salvage cost unit & 0.5 & 0.5 & 1 & 1 \\
\hline Unit selling price & 8 & 6 & 8 & 14 \\
\hline
\end{tabular}

Three different scenarios are considered as a basis for application of the model and its numerical results. The first scenario "pessimistic scenario" illustrates low demand
TABLE 1: Input parameter used to solve the model.

\begin{tabular}{lc}
\hline Parameters & Inputs \\
\hline$k=|T|$ & 10 \\
$m=|J|$ & 2 \\
$n=|I|$ & 4 \\
Transport cost from facility 1 & 300 (pro 1000 \\
(China) & product units) \\
Transport cost from facility 2 & 100 (pro 1000 \\
(Turkey) & product units) \\
Transport time from facility 1 & 3 \\
(China) & \\
Transport time from facility 2 & 1 \\
(Turkey) & 0.95 \\
$\alpha$ & 0.1 \\
$\beta$
\end{tabular}

TABLE 2: Unit production parameters.

forecasts for the next season. The second scenario "normal scenario" represents the case when the customer demand is normal. The third scenario "optimistic scenario" assumes high customer demand. To characterize the uncertainties of demand forecast of different products, a distribution probability is applied. Figures 1 and 2 show an example of the demand distribution, respectively, of the products under pessimistic scenario and demand distribution of the product 1 for the three scenarios.

The risk to be considered from solving the model can occur only because of wastage or shortage possibility. Therefore, according to our definition of the loss function $f(X, s)=$ $\sum_{i=1}^{n} f\left(X_{i}, s\right)=\mathrm{WC}^{s}+\mathrm{SC}^{s}-0.1 \cdot \mathrm{SR}^{s}$, the constraint (16) for this case study ensures that the probability that the risk costs incurring by, respectively, wastage and shortage costs do not exceed the $10 \%(\beta=0.1)$ of the expected profit revenue in $95 \%(\alpha=0.95)$ of all possible realization of stochastic parameters.

The model has been efficiently solved by means of frontline risk solver which supports the robust optimization through CVaR. 


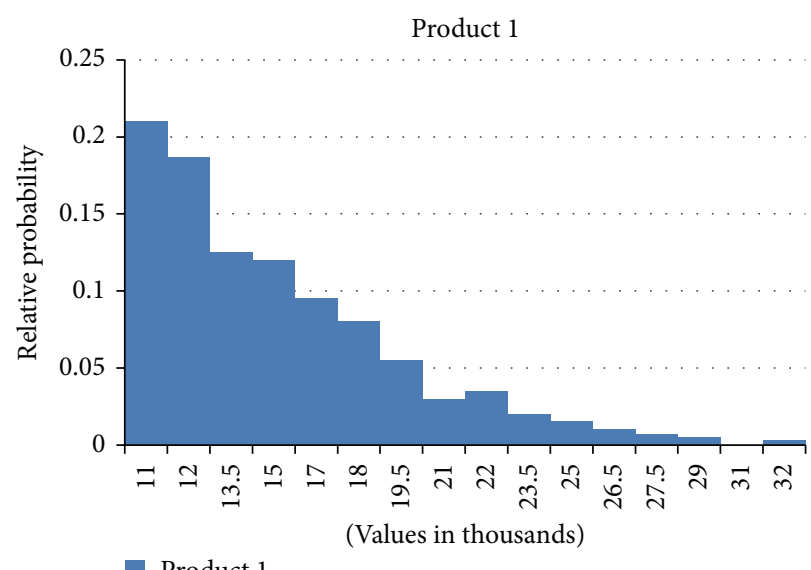

Product 1

(a)

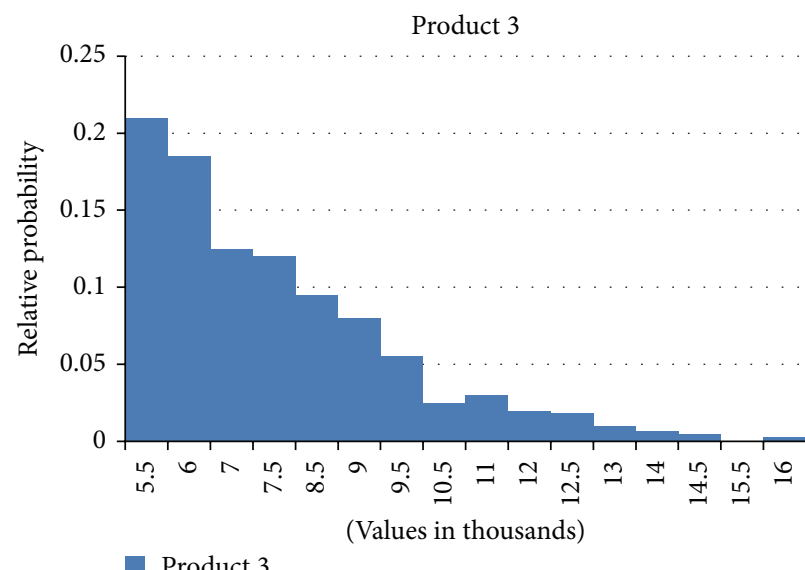

Product 3

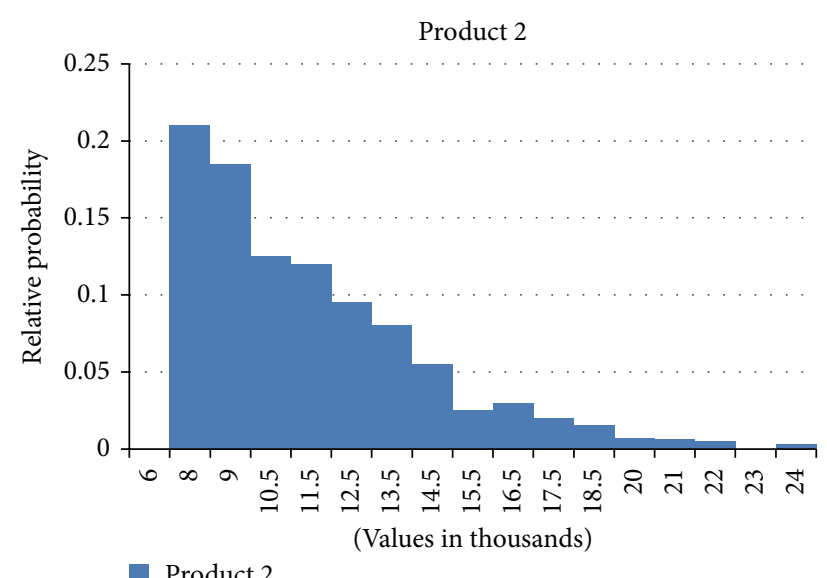

(b)

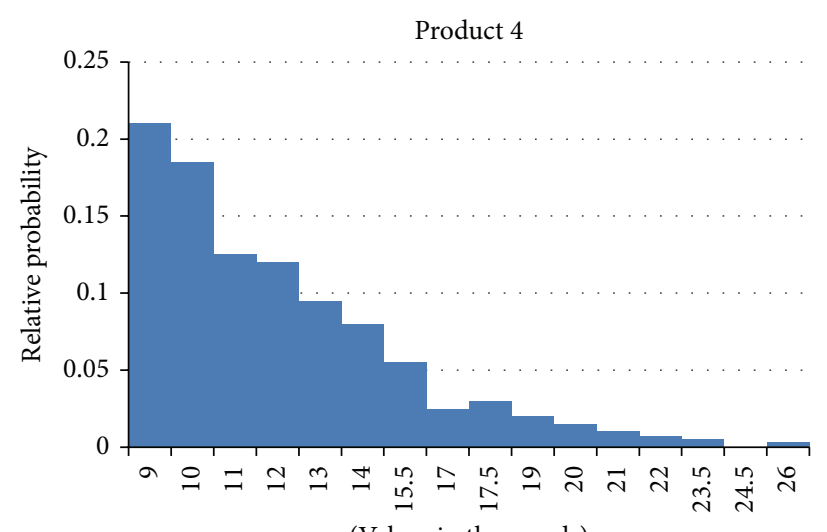

Product 4

(c)

(d)

FIGURE 1: Demand distribution of the products in a pessimistic scenario.

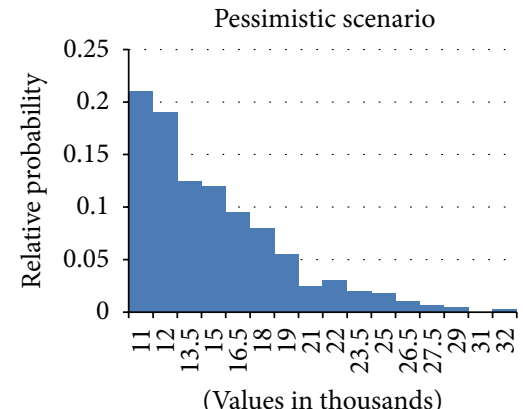

(Values in thousands)

Pessimistic scenario

(a)

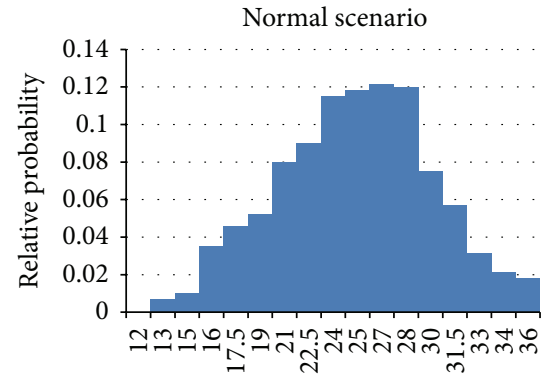

(Values in thousands)

- Normal scenario

(b)

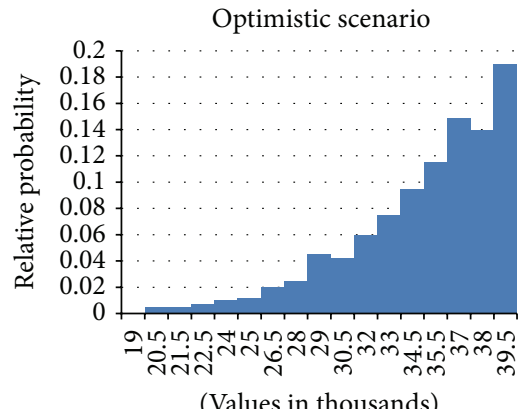

(Values in thousands)

Optimistic scenario

(c)

FIGURE 2: Demand distribution of product 1 in different scenarios.

5.1. Pessimistic Scenario. Table 3 lists the production plan in a pessimistic scenario. The expected average profit of the production for the next season is about 219000. Moreover, the solution can guarantee that the loss function will be negative in $96 \%$ cases of all possible realizations of stochastic parameters (Figure 3).
5.2. Normal Scenario. In the normal scenario, the demand of product 1 and product 4 , respectively, has nearly doubled, whereas the demand of product 2 and product 3 has been slightly increased. This is due to the low penalty factor of product 1 and product 4 which can be incurred for each delayed delivery and for the capacity restriction of 


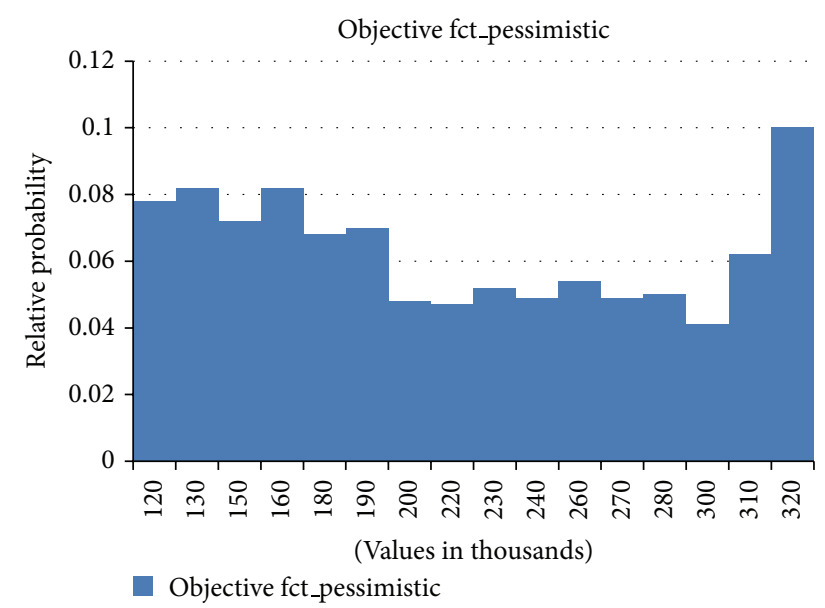

(a)

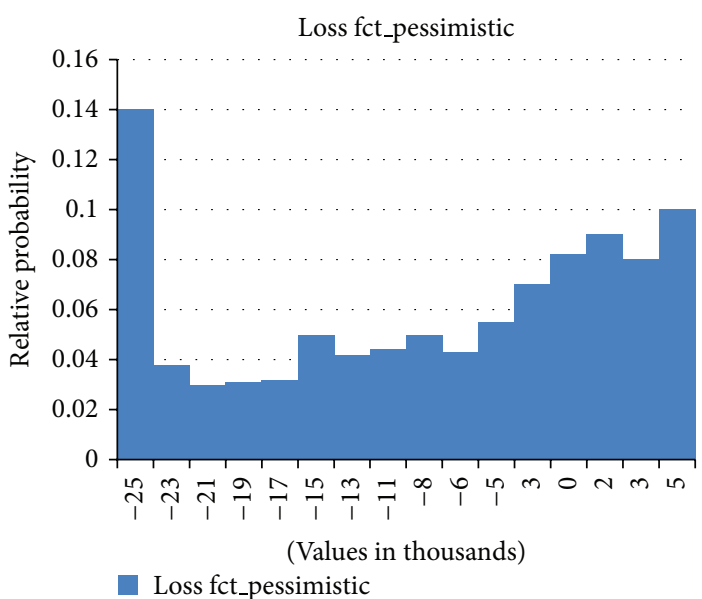

(b)

FIgUre 3: Profit and loss function distribution in a pessimistic scenario.

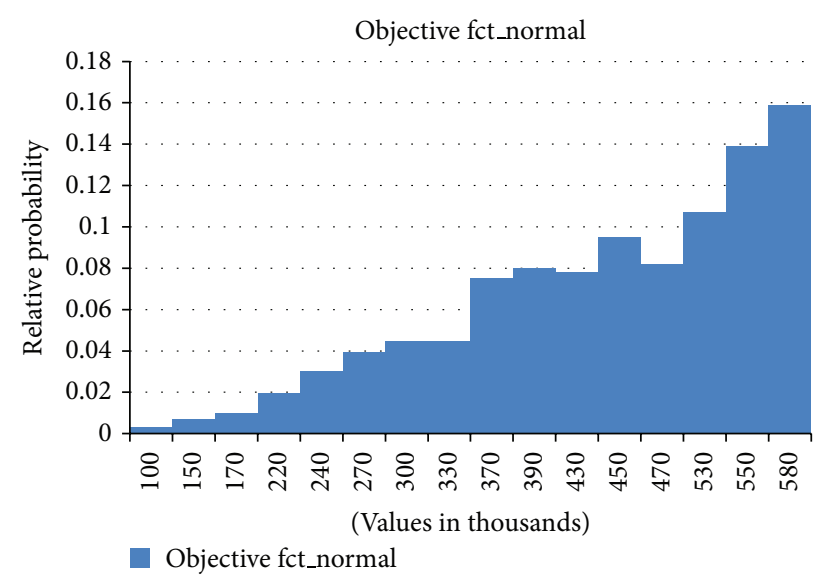

(a)

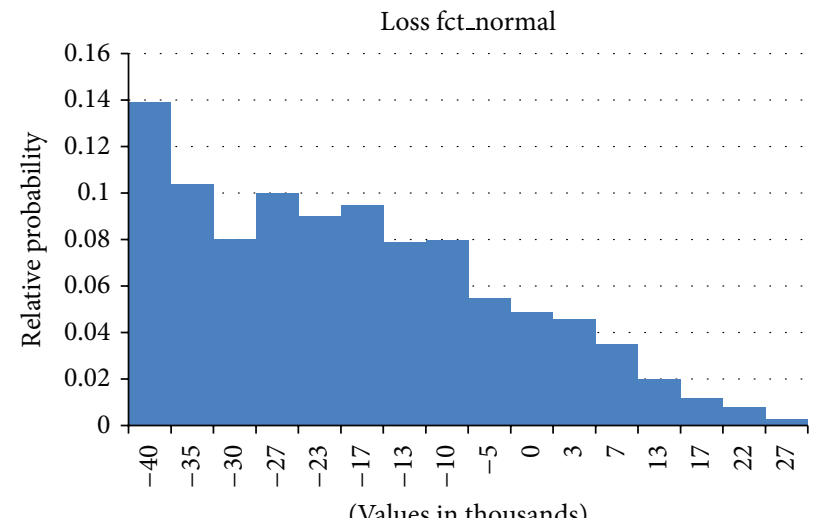

Loss fct_normal

(b)

Figure 4: Profit and loss function distribution in a normal scenario.

TABle 3: Production plan with the demand quantities in a pessimistic scenario.

\begin{tabular}{lcccc}
\hline & Product 1 & Product 2 & Product 3 & Product 4 \\
\hline $\begin{array}{l}\text { Demand next } \\
\text { season }\end{array}$ & 17969 & 16549 & 10169 & 14945 \\
$\begin{array}{l}\text { Start of production } \\
\text { Expected delivery }\end{array}$ & 3 & 2 & 1 & 1 \\
date & 6 & 6 & 5 & 4 \\
Produced In & & & & \\
$\quad$ Facility 1 & 0 & 1 & 1 & 1 \\
$\quad$ Facility 2 & 1 & 0 & 0 & 0 \\
\hline
\end{tabular}

the facilities (Table 4). In this case, the expected average profit is about 450000 , and the loss function is negative in $97.5 \%$ of all possible realizations of the stochastic parameters (Figure 4).

5.3. Optimistic Scenario. Since the optimistic scenario predicts a boom economic scenario, the production reaches its
TABle 4: Production plan with the demand quantities in a normal scenario.

\begin{tabular}{lcccc}
\hline & Product 1 & Product 2 & Product 3 & Product 4 \\
\hline Demand next season & 32355 & 19682 & 14415 & 26284 \\
Start of production & 1 & 4 & 3 & 1 \\
Expected delivery date & 6 & 8 & 7 & 6 \\
Produced in & & & & \\
$\quad$ Facility 1 & 0 & 1 & 1 & 1 \\
Facility 2 & 1 & 0 & 0 & 0 \\
\hline
\end{tabular}

maximum (Table 5). In this case, the average profit is about 665000 , and the loss function is satisfied with $99.1 \%$ of all possible realizations of the stochastic parameters (Figure 5).

\section{Conclusion and Outlook}

In this paper we have presented a risk-constrained profitexpected maximization model for a textile industry scenario. 


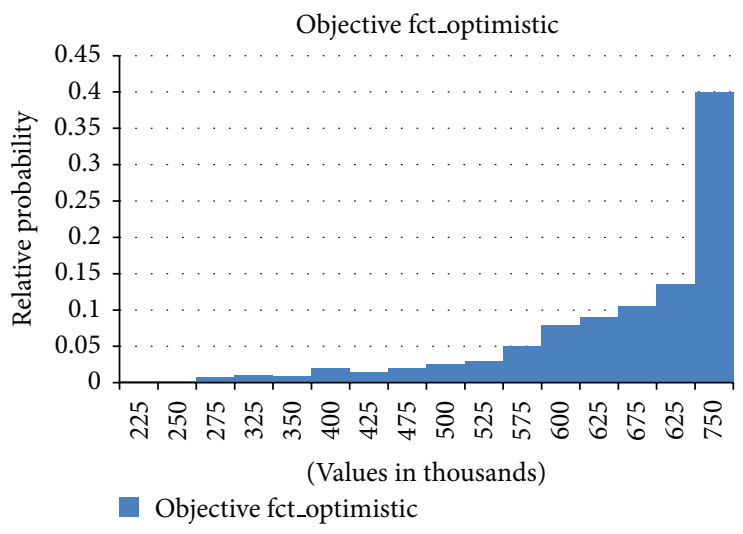

(a)

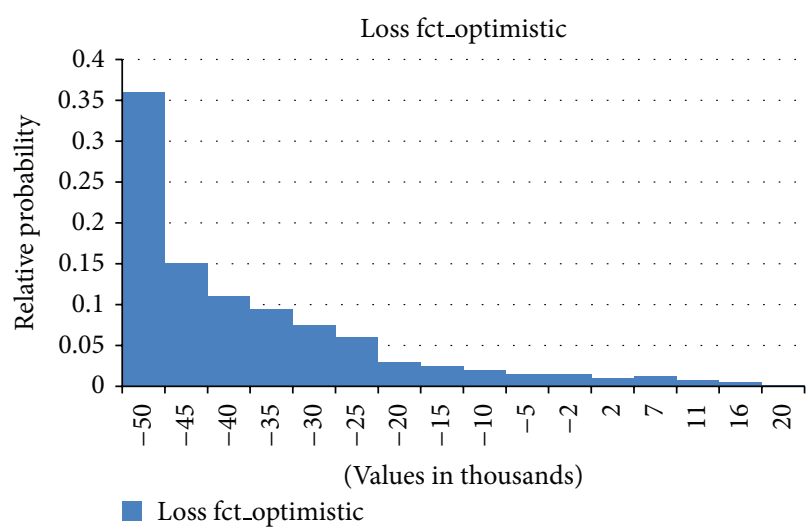

(b)

Figure 5: Profit and loss function distribution in an optimistic scenario.

Table 5: Production plan with the demand quantities in an optimistic scenario.

\begin{tabular}{lcccc}
\hline & Product 1 & Product 2 & Product 3 & Product 4 \\
\hline Demand next season & 37933 & 29312 & 19410 & 31600 \\
Start of production & 1 & 4 & 3 & 1 \\
Expected delivery date & 6 & 9 & 7 & 6 \\
Produced in & & & & \\
$\quad$ Facility 1 & 0 & 1 & 1 & 1 \\
Facility 2 & 1 & 0 & 0 & 0 \\
\hline
\end{tabular}

The forecast demand uncertainty has been explicitly considered in the model by means of the robust optimization and conditional value at risk theory by introducing and restricting a loss function. The robust optimization model originally proposed by [32] was adopted as the benchmark formulation of uncertainty considered in this paper. A case study has been used to demonstrate the viability of the proposed mathematical model. Results indicate that the production planning model using $\mathrm{CVaR}$ as the risk measure performs robustly and provides flexibility in decision analysis between different scenarios. The next step will be the further development of the profit maximization model to consider other types of uncertainties, for example, concerning the availability of the production plants, transportation means, and demand due dates.

\section{Conflict of Interests}

The authors declare that there is no conflict of interests regarding the publication of this paper.

\section{References}

[1] Datamonitor, Global Apparel Retail, 2010, http://www.datamonitor.com/.

[2] R. T. Rockafellar and S. Uryasev, "Conditional value-at-risk for general loss distributions," Journal of Banking and Finance, vol. 26, no. 7, pp. 1443-1471, 2002.
[3] S. Zhu and M. Fukushima, "Worst-case conditional value-atrisk with application to robust portfolio management," Operations Research, vol. 57, no. 5, pp. 1155-1168, 2009.

[4] A. Bruckner and S. Müller, Supply Chain Management in der Bekleidungsindustrie, Forschungsstelle der Bekleidungsindustrie, Cologne, Germany, 2003.

[5] J. Fissahn, Marktorientierte Beschaffung in der Bekleidungsindustrie, Münster University, Münster, Germany edition, 2001.

[6] A. Schneider, Internationalisierungsstrategien in der deutschen Textil-und Bekleidungsindustrie-eine empirische Untersuchung [M.S. dissertation], RWTH Aachen University, Aachen, Germany, 2003.

[7] G. Gereffi and O. Memedovic, The Global Apparel Value Chain-What Prospects for Upgrading by Developing Countries? UNIDO, Vienna, Austria, 2003.

[8] M. Grömling and J. Matthes, Globalisierung und Strukturwandel der Deutschen Textil-und Bekleidungsindustrie, Dt. Inst.-Verlag, Colougne, Germany, 2003.

[9] I. Langenhorst, Shop-logistik in der bekleidungswirtschaft: eine analyse der anforderungen herstellerinitiierter shop-systeme an die logistikprozesse der bekleidungsindustrie [Ph.D. thesis], Münster University, 1999.

[10] H.-C. Pfohl, M. Gomm, and X. Shen, China: Textil-und Bekleidungs-Supply Chain Zwischen Deutschland und China, Free Beratung, Korschenbroich, Germany, in H. WolfKluthausen, Jahrbuch der Logistik, 2007.

[11] M. Teucke and B. Scholz-Reiter, "Improving order allocation in fashion supply chains using radio frequency identification (RFID) technologies," in Fashion Supply Chain Management Using Radio Frequency Identification (RFID) Technologies, W. K. Wong and Z. X. Guo, Eds., vol. 152 of Woodhead Publishing Series in Textiles, Woodhead Publishing, Cambridge, UK, 2014.

[12] S. Thomassey, "Sales forecasts in clothing industry: the key success factor of the supply chain management," International Journal of Production Economics, vol. 128, no. 2, pp. 470-483, 2010.

[13] D. Ahlert and G. Dieckheuer, Marktorientierte Beschaffung in der Bekleidungsindustrie, FATM, Münster, Germany, 2001.

[14] J. T. Mentzer, C. C. Bienstock, and K. B. Kahn, "Benchmarking sales forecasting management," Business Horizons, vol. 42, no. 3, pp. 48-56, 1999. 
[15] J. Quick, M. Rinis, C. Schmidt, and B. Walber, SupplyTexErfolgreiches Supply-Management in KMU Der Textil- Und Bekleidungsindustrie, Forschungsinstitut für Rationalisierung (FIR) e.V. an der Universität Aachen, Aachen, Germany, 2010.

[16] Z.-L. Sun, T.-M. Choi, K.-F. Au, and Y. Yu, "Sales forecasting using extreme learning machine with applications in fashion retailing," Decision Support Systems, vol. 46, no. 1, pp. 411-419, 2008.

[17] S. Thomassey, M. Happiette, and J.-M. Castelain, "A global forecasting support system adapted to textile distribution," International Journal of Production Economics, vol. 96, no. 1, pp. 81-95, 2005.

[18] J. Mostard, R. Teunter, and R. de Koster, "Forecasting demand for single-period products: a case study in the apparel industry," European Journal of Operational Research, vol. 211, no. 1, pp. 139147, 2011.

[19] K. Hoyndorff, S. Hülsmann, D. Spee, and M. ten Hompel, Fashion Logistics. Grundlagen Über Prozesse und IT Entlang der Supply Chain, Munich, Huss-Verlag GmbH, 2010.

[20] J. Richardson, "Vertical integration and rapid response in fashion apparel," Organization Science, vol. 7, no. 4, pp. 400-412, 1996.

[21] Z.-L. Chen, "Integrated production and outbound distribution scheduling: review and extensions," Operations Research, vol. 58, no. 1, pp. 130-148, 2010.

[22] J. Mula, D. Peidro, M. Díaz-Madroñero, and E. Vicens, "Mathematical programming models for supply chain production and transport planning," European Journal of Operational Research, vol. 204, no. 3, pp. 377-390, 2010.

[23] S. A. Torabi and E. Hassini, "An interactive possibilistic programming approach for multiple objective supply chain master planning," Fuzzy Sets and Systems, vol. 159, no. 2, pp. 193-214, 2008.

[24] B. Scholz-Reiter, J. Hartmann, T. Makuschewitz, and E. M. Frazzon, "A generic approach for the graph-based integrated production and intermodal transport scheduling with capacity restrictions," in Procedia CIRP, vol. 7, pp. 109-114, 2013.

[25] A. D. Toni and A. Meneghetti, "Production planning process for a network of firms in the textile-apparel industry," International Journal of Production Economics, vol. 65, no. 1, pp. 17-32, 2000.

[26] E. M. Frazzon, A. G. N. Novaes, B. Scholz-Reiter, J. Hartmann, and T. Makuschewitz, "An approach for the rescheduling of integrated production and transport systems," in Proceedings of the 4th World Conference Production \& Operations Management. Serving the World, Production \& Operations Management Society, p. 10, Amsterdam, The Netherlands, 2012.

[27] H. Ishikura, "Study on the production planning of apparel products: determining optimal production times and quantities," Computers and Industrial Engineering, vol. 27, no. 1-4, pp. 1922, 1994.

[28] Y. W. Tan, J. B. Guan, and H. R. Karimi, "The Impact of the subsidy policy on total factor productivity: an empirical analysis of China's cotton production," Mathematical Problems in Engineering, vol. 2013, Article ID 248537, 8 pages, 2013.

[29] H. R. Karimi, N. A. Duffie, and S. Dashkovskiy, "Local capacity Ho control for production networks of autonomous work systems with time-varying delays," IEEE Transactions on Automation Science and Engineering, vol. 7, no. 4, pp. 849-857, 2010.

[30] S. Dashkovskiy, H. R. Karimi, and M. Kosmykov, "Stability analysis of logistics networks with time-delays," Journal of Production Planning \& Control, vol. 24, no. 7, pp. 567-574, 2013.
[31] A. Mehrsai, H. R. Karimi, and B. Scholz-Reiter, "Application of learning pallets for real-time scheduling by the use of radial basis function network," Neurocomputing, vol. 101, pp. 82-93, 2013.

[32] S. C. H. Leung, S. O. S. Tsang, W. L. Ng, and Y. Wu, "A robust optimization model for multi-site production planning problem in an uncertain environment," European Journal of Operational Research, vol. 181, no. 1, pp. 224-238, 2007.

[33] A.-G. Quaranta and A. Zaffaroni, "Robust optimization of conditional value at risk and portfolio selection," Journal of Banking and Finance, vol. 32, no. 10, pp. 2046-2056, 2008.

[34] R. A. Jabr, "Robust self-scheduling under price uncertainty using conditional Value-at-Risk," IEEE Transactions on Power Systems, vol. 20, no. 4, pp. 1852-1858, 2005.

[35] D. Peidro, J. Mula, R. Poler, and J.-L. Verdegay, "Fuzzy optimization for supply chain planning under supply, demand and process uncertainties," Fuzzy Sets and Systems, vol. 160, no. 18, pp. 2640-2657, 2009.

[36] F. Pan and R. Nagi, "Robust supply chain design under uncertain demand in agile manufacturing," Computers and Operations Research, vol. 37, no. 4, pp. 668-683, 2010.

[37] P. M. Verderame and C. A. Floudas, "Operational planning of large-scale industrial batch plants under demand due date and amount uncertainty: II. Conditional value-at-risk framework," Industrial and Engineering Chemistry Research, vol. 49, no. 1, pp. 260-275, 2010.

[38] P. M. Verderame and C. A. Floudas, "Multisite planning under demand and transportation time uncertainty: Robust optimization and conditional value-at-risk frameworks," Industrial and Engineering Chemistry Research, vol. 50, no. 9, pp. 4959-4982, 2011.

[39] S. M. J. Mirzapour Al-E-Hashem, H. Malekly, and M. B. Aryanezhad, "A multi-objective robust optimization model for multi-product multi-site aggregate production planning in a supply chain under uncertainty," International Journal of Production Economics, vol. 134, no. 1, pp. 28-42, 2011.

[40] D. Rahmani, R. Ramezanian, P. Fattahi, and M. Heydari, "A robust optimization model for multi-product two-stage capacitated production planning under uncertainty," Applied Mathematical Modelling, vol. 37, no. 20-21, pp. 8957-8971, 2013. 


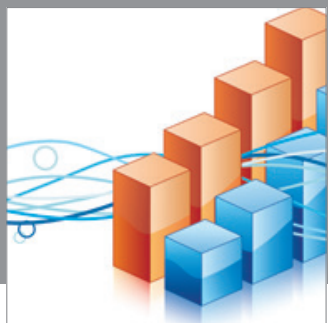

Advances in

Operations Research

mansans

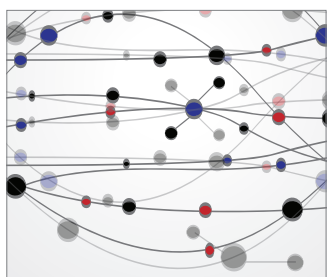

The Scientific World Journal
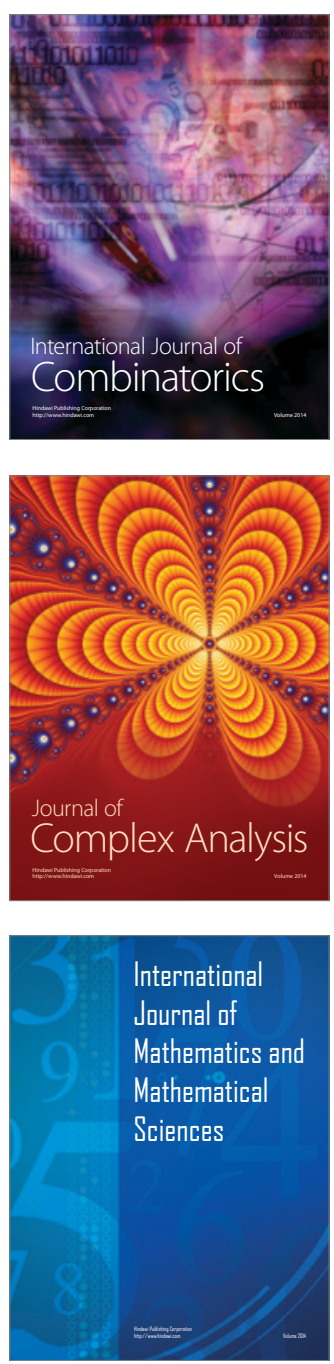
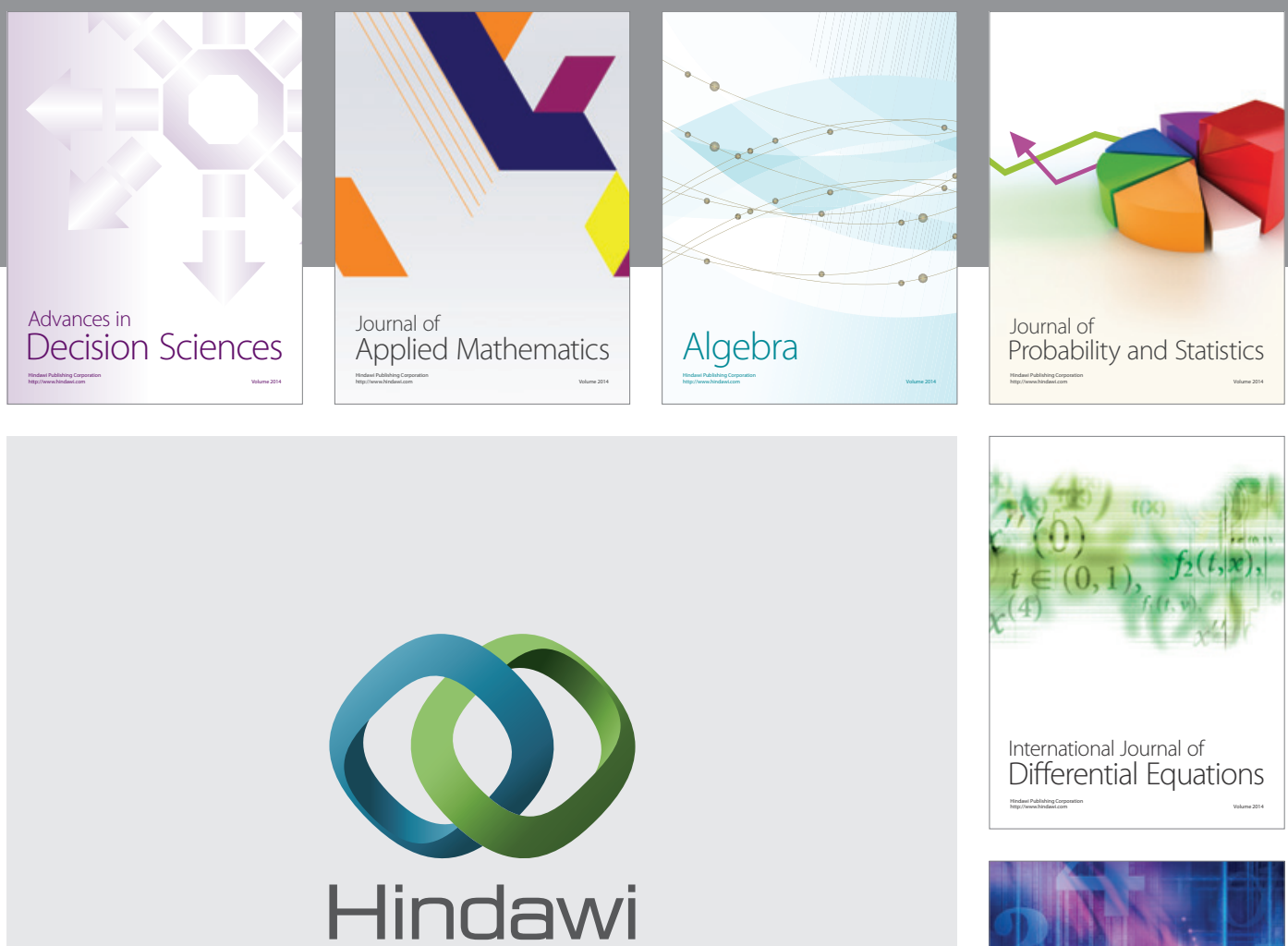

Submit your manuscripts at http://www.hindawi.com
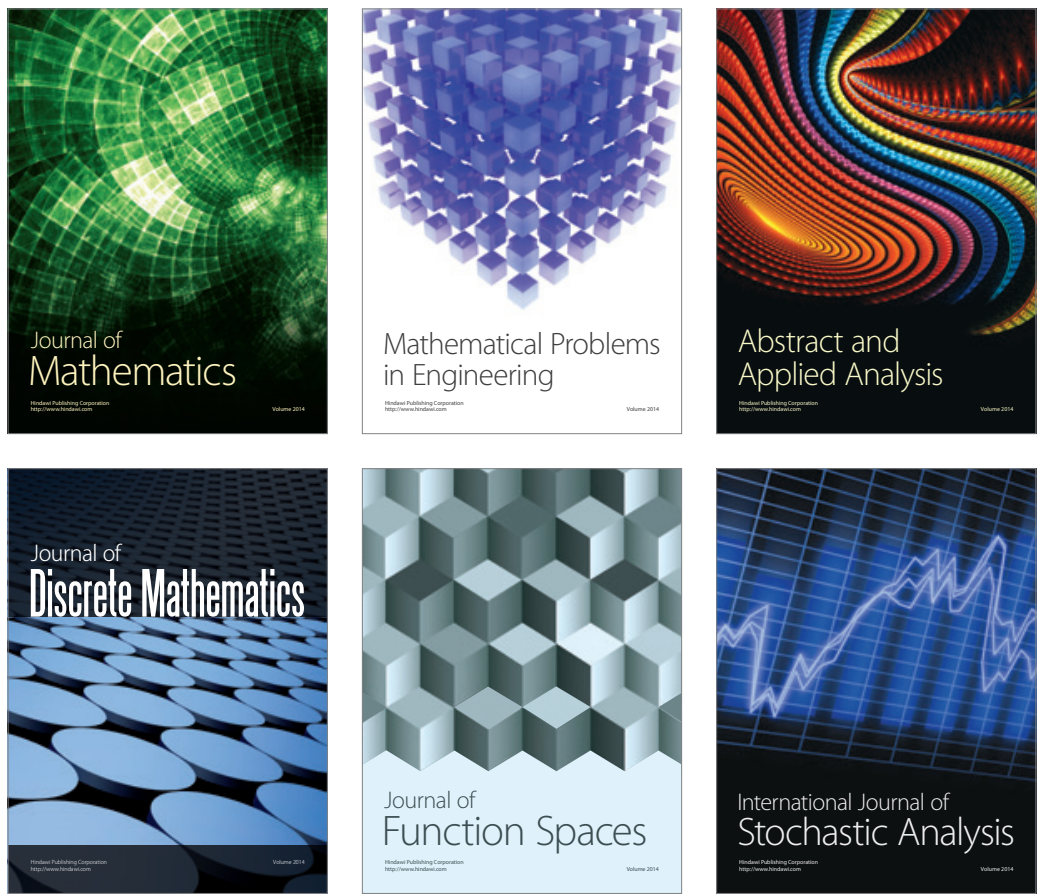

Journal of

Function Spaces

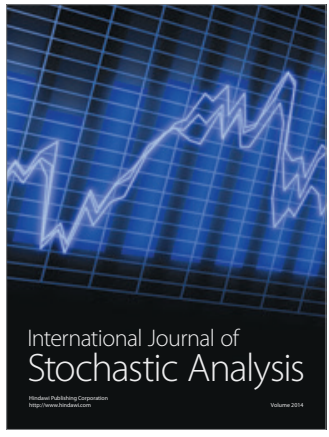

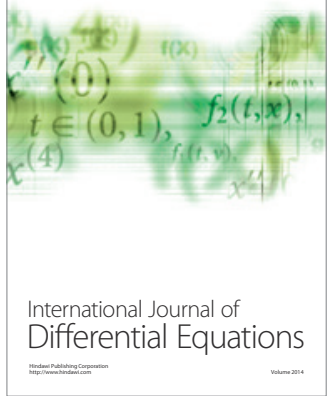
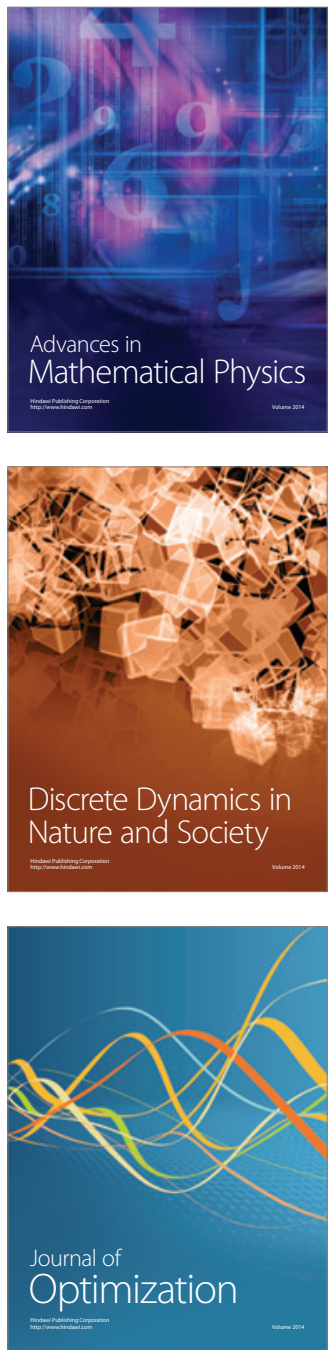